\title{
FACTORS INFLUENCING PROJECT MANAGEMENT SUCCESS: THE RELEVANCE OF DIGITAL COMPETENCES
}

\author{
Marko Slavković ${ }^{1}$ \\ Marijana Simić
}

DOI: https://doi.org/10.31410/ERAZ.S.P.2019.87

\begin{abstract}
Digital era changes the assumption for business success forces of production firms and transform their technological base. Success of this type of project depends on different factors related to internal organization, stakeholders and digital competencies. The purpose of this article is to compare the relevance of these factors for project management success. The goal is to identify the importance of employees' digital competences in technological changes. The results obtained in the original research can be a useful guide for managers to focus their efforts on factors that can ensure superior performance of a particular project.
\end{abstract}

Keywords: project management, digital competences, digitalization, technology change.

\section{INTRODUCTION}

Globalization and digitization as contemporary trends play an important role in the way Jusinesses operate. Challenges and issues facing enterprises are the basic characteristics of today's Fourth Industrial Revolution that integrates the digital and physical world in one way [1] into a consistent whole [2]. Moreover, the intensification of the use of digital technology in the last two decades has contributed to the transformation of numerous processes in the company and the value chain, which has affected all activities, from procurement to sales and marketing. Special requirements are in front of production companies, which, by replacing traditional methods of work with modern digital tools [3], tend to maximize potential benefits generated by the use of technologies such as automation, robotics, 3D-printing, Internet of Things (IoT) and others [4], [5].

The identified trends have led to changes, not only in the structure of production and productivity, but also in the domain of quality and quantity of work. There is a need for transforming business models, but also redefining job descriptions [3]. Advanced technologies associated with the Fourth Industrial Revolution, on the one hand, guarantee significant improvements in efficiency and effectiveness of production, but on the other hand, they also require new key competences and capabilities of employees [6], [2]. Consequently, there is a need to innovate formal education programs and their content, taking into account the existing needs of individuals. This is further enhanced by the fact that in companies that are seeking a sustainable competitive advantage, the focus is increasingly on enhancing professional skills and business models through continuous education and lifelong learning programs for newly employed and existing employees [3].

In addition, project management is classified as the fundamental activity of manufacturing enterprises [7], [8], especially if they want to secure their position in today's digitalization era. An important task for managers is the identification of factors that determine the success of projects,

Faculty of Economics, University of Kragujevac, Djure Pucara Starog 3, 34000 Kragujevac, Serbia Faculty of Economics, University of Kragujevac, Djure Pucara Starog 3, 34000 Kragujevac, Serbia 
which imply the implementation of advanced technology. Since the future of production rests on the exploitation of intangible assets and the ability to innovate and differentiate [9], as a key precondition for successfully overcoming the barriers to digital transformation, and thus maximizing the potential benefits of advanced technologies, it represents human capital [3]. A review of previous studies identified a wide range of factors that determine the success of the projects. Among them are allocated financially [9], [7], [8], organizational [10], [11], [12], stakeholders [13], technological [14]. As the development of advanced production technologies develops the need for changing employee behavior patterns and their competencies [15], project managers must undoubtedly pay special attention to the development of competencies of their employees, in order to ensure the path to successful implementation of the project. In this context, the phenomenon of digital competences is highlighted [16]. Although their significance in the field of project management cannot be disputed [17], empirical evidence is limited that points to the importance of digital competencies for the successful implementation of the project.

\section{LITERATURE REVIEW}

In today's era, project management is defined not only as a mode of production, which results in the creation of a finished product [13], but it is also assumed to be an organizational form and management technique [18]. One of the important issues in the field of project management refers to the method of measuring project performance. For the past two decades, the focus has been on financial criteria, based on the estimation of efficiency and the design of the budget required for the implementation of the project [19]. In addition, the success of the project can also be viewed through the prism of stakeholder satisfaction, while recognizing the success of products on the market, business and organizational benefits, and the development of project team members [20].

Although a significant part of the professional public places focusses on financial factors of success [9], [7], [8], other factors need not be omitted. Among the important internal factors, which can improve the efficiency and effectiveness of project implementation, is the organizational culture [12]. Presented as the development of a unique set of values, attitudes and ideas, it is clear that it plays an important role in many aspects of the organization [21]. An organization whose culture rests on flexibility and spontaneity will most likely contribute to more effectively overcoming obstacles caused by uncertainty. Therefore, the organizational culture, which fosters active participation of employees and their empowerment during the implementation of advanced technology, certainly contributes positively to the successful realization of the projects [22], [10]. In addition to organizational culture, previous research emphasizes the importance of organizational structure, which primarily affects the ease of resource allocation and agility in decision making. According to [23], the organizational structure is an important factor, as there are greater prospects for the success of the project, if the organizational structure is fully adapted to the requirements for the realization of the project.

Although the wide range of internal factors, which determine the success of the project, the following conditions should not be omitted [24]: (1) the criteria for success should be consistent with the interests of stakeholders before and during the project; (2) the relationship between project owner / project sponsor and manager should be characterized by co-operation and continuous exchange of information and ideas; (3) the project manager should be prepared to handle flexibly in unforeseen circumstances; (4) The project promoter / sponsor should really be interested in the results of the project. Based on the above, it is concluded that ,the value is in the eyes of the observers", i.e. that the actions and interests of the stakeholders significantly deter- 
mine the chances of realization and success of the projects. Bearing in mind the numerous, but often, contradictory perspectives of stakeholders, the success of the projects can be considered in different ways, and therefore special attention should be paid to the consideration and harmonization of the interests of internal and external stakeholders [10].

Among external stakeholders, an important group is represented by suppliers, since the level of integration with these stakeholders contributes to positive results in terms of the flexibility and reliability of the delivered supplies [25]. In accordance, Horn et al., [26] emphasize that enterprises with a high level of integration with suppliers are particularly successful in the execution of projects. Therefore, the relationship with suppliers and their choice should be classified as another critical factor. The selection process should be carried out carefully, taking into account various aspects such as quality, price, delivery, service level, warranty, technical capacity, production capacity, historical performance, and even location [27]. It is also important to note that the definition of contractual items related to the establishment of different incentive mechanisms (bonuses and penalties) for suppliers [28] plays an important role in the realization of projects, since it can achieve reduction of time and cost of delivery and improvement of the quality of the delivered articles [29]. In addition to relationships with suppliers, the success of the project is also correlated with the level of client engagement. The greater the degree of participation of clients in the project, it is easier to identify the requirements, to establish the quality criteria and to reduce the need for change, and thus to improve the performance. Therefore, the active participation of clients in projects has to be stimulated from the beginning of the life cycle of the project [30].

The implementation of advanced technology, which features the Fourth Industrial Revolution, on the one hand, provides significant improvements in the efficiency and effectiveness of production, but on the other hand, it also requires new key competences and skills to be developed by employees [6], [2]. Since advanced production technology is a novelty, while competence management is one of the most important levers on which successful transformation processes lie [31], [2], it is necessary to create appropriate behavioral patterns, which will primarily be based on the improvement of existing experience and abilities of employees [15]. Chryssolouris et al. [32]. state that engineers in manufacturing companies should attend various training programs in order to continuously work on the improvement of knowledge and skills and thus meet the growing needs of the modern production industry. Sousa and Rocha [33] have found that the set of necessary competences of employees is changing under the influence of the effects of the Internet of things, cloud technologies, large data, mobile technologies, artificial intelligence and robotics. Sousa and Wilks [34] concluded in their study that the skills of critical thinking, adaptation, network collaboration and creativity skills will be essential in today's business environment.

Moreover, the influence of advanced technology has significantly contributed to the development of the phenomenon of digital competences, that is, technology-related skills [16], which can also be classified as one of the primary requirements in the field of project management in the production sector [35]. Their relevance rests on the fact that they significantly contribute to acquiring other key competences (e.g. language, mathematics, learning to learn, cultural awareness) [36]. However, empirical evidence of the specific competencies of employees for successful implementation of projects in manufacturing enterprises is limited [37], while a small number of studies are also concerned with establishing the relevance of digital competencies necessary to overcome obstacles in transformation processes [38], [2]. 


\section{RESEARCH METHODOLOGY}

The given theoretical framework and the gap in the existing literature is the starting point for carrying out the research, the results of which are presented in this paper. The subject of the research is to determine the relevance of different groups of factors, with particular emphasis on establishing and comparing the importance of digital competencies for the successful implementation of projects. Participation in the survey was taken by employees in managerial positions in manufacturing enterprises, which actively operate in the territory of the Republic of Serbia. The primary goal of the research is to determine the perception of employees about the relevance of identified groups of factors for the realization of projects. The software package SPSS was used for data processing. In accordance with the subject and objective of the research, descriptive statistics analysis and reliability analysis were conducted.

A questionnaire was used as a research instrument, which was specifically designed for this research. The first part of the questionnaire was intended to provide basic information about the company (i.e. ownership structure, number of employees etc.) and information on the way of organizing the production process and the existing form of automation. Within the second section of the questionnaire, statements were presented, which presented critical factors for the implementation of projects, whereby respondents were asked to express their views on the relevance of these factors in the five-point Likert scale. The method of distributing the questionnaire was conducted with the help of a transparent database of businessmen and companies, published by the Business Registers Agency. This was randomly selected 189 active production companies, and 54 valid questionnaires were collected (response rate 28.6\%).

\section{RESEARCH RESULTS}

Table 1 gives an overview of the evidence, which reflects various factors relevant to the success of the projects, as well as the average values that reflect the attitude of the respondents. Based on the results of descriptive statistical analysis, the conclusion is drawn that managers attach the greatest importance to the factors concerning the stakeholders and their relations with them. Particular emphasis is placed on the importance of customers, as the most important external stakeholders, which clearly indicates the basic vision of the company to strive to fully meet the needs of its customers. No suppliers should be omitted, which have an impact on the efficiency of the execution of the production process, but also in the timely satisfaction of the needs of customers. Regarding organizational factors, which are also highly evaluated (3.8185), it is essential to note that it is important to build an organization and cultivate a culture that facilitates the acquisition of the necessary resources (material and immaterial).

Regarding digital competencies, the mean value shown $(3,8796)$ indicates the central relevance of these factors from the perspective of the manager. This result also points to the potential shortage of Serbian manufacturing companies in which digital awareness is still not developed, that is, employees continue to use traditional methods, tools and equipment. Insufficient knowledge about new technologies, a constant break with modern trends and/or resistance to change are just some of the possible reasons why digital competencies are not on the highest level of significance. Also, Table 1 gives the results of reliability analysis. The values of Cronbach's alpha coefficient can be accepted [39] and range from 0,700 to 0,734. 
Table 1: Descriptive statistics and reliability analysis

\begin{tabular}{|c|c|c|}
\hline Factors & Mean & Standard deviation \\
\hline \multicolumn{3}{|c|}{ Stakeholders: Cronbach's alpha $=\mathbf{0 , 7 3 4}$} \\
\hline Finding and selecting suppliers & 4,2593 & 0,67810 \\
\hline Improving product quality from customer perspective & 4,2963 & 0,79217 \\
\hline Offering value to customers & 4,1481 & 0,81048 \\
\hline $\begin{array}{l}\text { Return rate of invested money into the new production } \\
\text { system }\end{array}$ & 3,9444 & 0,83365 \\
\hline Strengthening the image of the organization in public & 3,9259 & 0,90807 \\
\hline Sum & 4,1148 & 0,56248 \\
\hline \multicolumn{3}{|c|}{ Organisational structure and culture: Cronbach's alpha $=\mathbf{0 , 7 3 3}$} \\
\hline $\begin{array}{l}\text { Willingness of the employees to accept and participate } \\
\text { in the implementation of the new production system }\end{array}$ & 3,6852 & 1,07850 \\
\hline $\begin{array}{l}\text { Provision of necessary resources (material and immate- } \\
\text { rial) for the implementation of a new production system }\end{array}$ & 4,2407 & 0,72516 \\
\hline Improving communication among employees & 3,5000 & 1,02331 \\
\hline Time needed to implement a new production system & 3,9444 & 0,89899 \\
\hline Simplicity of implementation a new production system & 3,7222 & 0,97935 \\
\hline Sum & 3,8185 & 0,65964 \\
\hline \multicolumn{3}{|c|}{ Digital competences: Cronbach's alpha $=\mathbf{0 , 7 0 0}$} \\
\hline $\begin{array}{l}\text { Readiness of employees to follow the demands of their } \\
\text { superiors }\end{array}$ & 3,9815 & 0,92125 \\
\hline $\begin{array}{l}\text { Availability of relevant information on the new produc- } \\
\text { tion system }\end{array}$ & 3,7963 & 0,89821 \\
\hline $\begin{array}{l}\text { Employee competence to introduce a new production } \\
\text { system }\end{array}$ & 3,8519 & 0,81048 \\
\hline $\begin{array}{l}\text { Monitoring the achieved performance of the new pro- } \\
\text { duction system }\end{array}$ & 3,8889 & 0,92485 \\
\hline Sum & 3,8796 & 0,64563 \\
\hline
\end{tabular}

\section{CONCLUSION}

Based on the results of the survey, it is concluded that digital competences have a significant impact on the success of projects in manufacturing enterprises. However, it cannot be said that managers point out the above factors as the most important. In the first place are stakeholders' factors, that is, relationship with suppliers and buyers, as the most important external stakeholders. The compensation for the obtained results rests with the fact that the companies included in the sample still do not have modern technological equipment and tools, and underestimates the importance of digital competencies. In addition, managers and contractors are mostly used to traditional methods, which makes companies in Serbia on a lower scale than in the region.

In addition to the insufficiently developed awareness of the need for the application of modern technological solutions (internet of things, cloud technologies, large data, mobile technologies, artificial intelligence and robotics), the findings incorporated in the questionnaire primarily relate to the possibilities of using modern technological equipment in order to more effectively communicate and exchange information and knowledge among employees. In this way, gap has been created to expand and conduct future research, which will include other digital competences (e.g. digital literacy, digital divide, digital citizenship). In addition, it would be possible to carry out a comparison with other groups of critical project success factors, such as financial, organizational and stakeholder-related factors, which would lead to the ranking of the analyzed 
factors by the degree of importance for achieving success in the domain of project management. Such a method of research would provide significant implications for the managers of production companies, which would indicate to all critical areas during project implementation and provide guidelines for the implementation of AMT (advanced manufacturing technology).

\section{REFERENCES}

[1] Schallmo, D., Williams, C. A., \& Boardman, L. (2017). Digital transformation of business models-Best practice, enablers, and roadmap. International Journal of Innovation Management, 21(08), 1740014.

[2] Butschan, J., Heidenreich, S., Weber, B., \& Kraemer, T. (2019). Tackling hurdles to digital transformation-The role of competencies for successful industrial internet of things (IIoT) implementation. International Journal of Innovation Management, 23(04), 1950036

[3] Demir, O. (2019). Digital Skills, Organizational Behavior and Transformation of Human Resources: A Review. Ecoforum Journal, 8(1).

[4] Laudien, S. M., \& Daxböck, B. (2016). The influence of the industrial internet of things on business model design: A qualitative-empirical analysis. International Journal of Innovation Management, 20(08), 1640014.

[5] Turovets, Y., Vishnevskiy, K., Tokareva, M., \& Kukushkin, K. (2019). Technology foresight for digital manufacturing: Russian case. In IOP Conference Series: Materials Science and Engineering (Vol. 497, No. 1, p. 012062). IOP Publishing.

[6] Delery, J. E., \& Doty, D. H. (1996). Modes of theorizing in strategic human resource management: Tests of universalistic, contingency, and configurational performance predictions. Academy of management Journal, 39(4), 802-835.

[7] Belout, A., \& Gauvreau, C. (2004). Factors influencing project success: the impact of human resource management. International journal of project management, 22(1), 1-11

[8] McCollum, J. K., \& Sherman, J. D. (1991). The effects of matrix organization size and number of project assignments on performance. IEEE Transactions on Engineering Management, 38(1), 75-78.

[9] Achanga, P., Shehab, E., Roy, R., \& Nelder, G. (2006). Critical success factors for lean implementation within SMEs. Journal of manufacturing technology management, 17(4), 460-471.

[10] McDermott, C. M., \& Stock, G. N. (1999). Organizational culture and advanced manufacturing technology implementation. Journal of Operations Management, 17(5), 521-533.

[11]Parthasarthy, R., \& Sethi, S. P. (1992). The impact of flexible automation on business strategy and organizational structure. Academy of Management review, 17(1), 86-111.

[12] Zammuto, R. F., \& O'Connor, E. J. (1992). Gaining advanced manufacturing technologies' benefits: The roles of organization design and culture. Academy of Management Review, 17(4), 701-728.

[13] Pacagnella Jr, A. C., da Silva, S. L., Pacífico, O., de Arruda Ignacio, P. S., \& da Silva, A. L. (2019). Critical Success Factors for Project Manufacturing Environments. Project Management Journal, 50(2), 243-258.

[14] Whyte, J., Stasis, A., \& Lindkvist, C. (2016). Managing change in the delivery of complex projects: Configuration management, asset information and 'big data'. International Journal of Project Management, 34(2), 339-351.

[15] Zhong, R. Y., Xu, X., Klotz, E., \& Newman, S. T. (2017). Intelligent manufacturing in the context of industry 4.0: a review. Engineering, 3(5), 616-630. 
[16] Van Laar, E., van Deursen, A. J., van Dijk, J. A., \& de Haan, J. (2017). The relation between 21st-century skills and digital skills: A systematic literature review. Computers in human behavior, 72, 577-588.

[17] Westkämper, E. (2007). Digital Manufacturing in the global Era. In Digital Enterprise Technology (pp. 3-14). Springer, Boston, MA.

[18] Satoglu, S., Ustundag, A., Cevikcan, E., \& Durmusoglu, M. B. (2018). Lean Transformation Integrated with Industry 4.0 Implementation Methodology. In Industrial Engineering in the Industry 4.0 Era (pp. 97-107). Springer, Cham.

[19] Gemünden, H. G. (2015). Success factors of global new product development programs, the definition of project success, knowledge sharing, and special issues of project management journal®. Project management journal, 46(1), 2-11.

[20] Geoghegan, L., \& Dulewicz, V. (2008). Do project managers' leadership competencies contribute to project success?. Project Management Journal, 39(4), 58-67.

[21] Denison, D. R., \& Mishra, A. K. (1995). Toward a theory of organizational culture and effectiveness. Organization science, 6(2), 204-223.

[22] Leonard-Barton, D., \& Sinha, D. K. (1993). Developer-user interaction and user satisfaction in internal technology transfer. Academy of Management Journal, 36(5), 1125-1139.

[23] Creasy, T., \& Anantatmula, V. S. (2013). From every direction-how personality traits and dimensions of project managers can conceptually affect project success. Project Management Journal, 44(6), 36-51.

[24] Jugdev, K., \& Müller, R. (2005). A retrospective look at our evolving understanding of project success. Project management journal, 36(4), 19-31.

[25] Schoenherr, T., \& Swink, M. (2012). Revisiting the arcs of integration: Cross-validations and extensions. Journal of Operations Management, 30(1-2), 99-115.

[26] Horn, P., Scheffler, P., \& Schiele, H. (2014). Internal integration as a pre-condition for external integration in global sourcing: A social capital perspective. International Journal of Production Economics, 153, 54-65.

[27] Luzon, B., \& El-Sayegh, S. M. (2016). Evaluating supplier selection criteria for oil and gas projects in the UAE using AHP and Delphi. International Journal of Construction Management, 16(2), 175-183.

[28] Bubshait, A. A. (2003). Incentive/disincentive contracts and its effects on industrial projects. International Journal of Project Management, 21(1), 63-70.

[29] Meng, X., \& Gallagher, B. (2012). The impact of incentive mechanisms on project performance. International Journal of Project Management, 30(3), 352-362.

[30] Ribeiro, P., Paiva, A., Varajão, J., \& Dominguez, C. (2013). Success evaluation factors in construction project management-some evidence from medium and large Portuguese companies. KSCE Journal of Civil Engineering, 17(4), 603-609.

[31] Abstein, A., Heidenreich, S., \& Spieth, P. (2014). Innovative work behaviour: The impact of comprehensive HR system perceptions and the role of work-life conflict. Industry and Innovation, 21(2), 91-116.

[32] Chryssolouris, G., Mavrikios, D., \& Mourtzis, D. (2013). Manufacturing systems: skills \& competencies for the future. Procedia CIRp, 7, 17-24.

[33] Sousa, M. J., \& Rocha, Á. (2019). Skills for disruptive digital business. Journal of Business Research, 94, 257-263.

[34] Sousa, M. J., \& Wilks, D. (2018). Sustainable skills for the world of work in the digital age. Systems Research and Behavioral Science, 35(4), 399-405.

[35] Ilomäki, L., Kantosalo, A., \& Lakkala, M. (2011). What is digital competence?. Linked portal.

[36] Ferrari, A. (2012). Digital competence in practice: An analysis of frameworks. 
[37] Schwuchow, K \& J Gutmann (2015). Personalentwicklung 2016 Themen, Trends, Best Practices. (1). Freiburg im Breisgau: Haufe-Lexware.

[38] Falk, M., \& Biagi, F. (2017). Relative demand for highly skilled workers and use of different ICT technologies. Applied Economics, 49(9), 903-914.

[39] Mallery, P., \& George, D. (2003). SPSS for Windows step by step: a simple guide and reference. Allyn, Bacon, Boston. 